\title{
Afinal, para que servem as condicionalidades em educação do Programa Bolsa Família?
}

\author{
André Pires*
}

\section{Resumo}

Esse artigo objetiva refletir sobre estratégias de enfrentamento da pobreza a partir da exigência de frequência escolar mínima presente no desenho do programa de transferência de renda condicionada do governo federal Bolsa Família. Num primeiro momento, são apresentadas algumas considerações, fundamentadas em trabalhos científicos, que problematizam a efetividade das condicionalidades em educação presentes no Programa Bolsa Família (PBF). Na sequência, apresento resultados de pesquisa desenvolvida entre 2008 e 2010 que entrevistou vinte e duas pessoas participantes do PBF e cujo objetivo foi compreender a visão dos próprios beneficiários em relação a esta política de transferência de renda. Os resultados dessa investigação levaram-me a considerar que as condicionalidades do PBF podem ser vistas como instauradoras de uma relação de troca e reciprocidade entre os beneficiários dessa política e o Estado. Pensado nesses termos, proponho neste artigo que as discussões sobre as condicionalidades em educação do PBF devem ser pensadas numa perspectiva ampliada, não se restringindo somente aos seus efeitos práticos em termos de frequência escolar ou ganhos de escolaridade, mas também aos seus efeitos simbólicos, notadamente, o fortalecimento dos sentimentos de pertencimento e reconhecimento sociais por parte das entrevistadas gerados pelo cumprimento das condicionalidades em educação. Palavras-chave: Educação. Políticas Públicas. Programas de Transferência de Renda Condicionada. Campinas (SP).

\section{Introdução}

0 Programa Bolsa Família (PBF), programa de transferência de renda condicionada do governo federal, foi implantado pelo governo federal em 2003 com o propósito de enfrentar a pobreza articulando ações em dois períodos temporais. ${ }^{1}$ Em curto prazo, a

\footnotetext{
* Doutor em Ciências Sociais, Universidade Estadual de Campinas (UNICAMP); Professor do Programa de Pós Graduação em Educação da Pontifícia Universidade Católica de Campinas (PUC-Campinas).

E-mail: anpires@puc-campinas.edu.br

1 Embora importante, escaparia dos propósitos deste artigo tratar sobre concepções de justiça, pobreza e as disputas entre estas concepções presentes nos processos de formulação e implementação do Programa Bolsa Família. 0 leitor poderá encontrar relevantes informações sobre estes processos no trabalho de Amélia Cohn (COHN, 2010).
} 
transferência de dinheiro a familias pobres teria o intuito de aliviar os efeitos imediatos da pobreza, a elas propiciando a condições para aquisição de bens e serviços básicos para a sua subsistência. Em longo prazo, as condicionalidades previstas, notadamente aquelas vinculadas à educação, teriam como propósito enfrentar os mecanismos de reprodução da pobreza. Em relação à educação, a exigência de frequência escolar mínima, para crianças e jovens de famílias atendidas pelo Programa Bolsa Família, foi estabelecida com intuito de romper o chamado ciclo intergeracional da pobreza. ${ }^{2}$ Neste entendimento, 0 incremento da frequência escolar de crianças e jovens de familias pobres promover melhores condições para que essas pessoas ingressem no mercado de trabalho, quando adultas, aumentando a renda e, consequentemente, fazendo com que saiam da condição de pobreza em relação à geração de seus pais. Associado a isso, a exigência de frequência escolar para crianças e jovens também foi estabelecida com o intuito de contribuir para o enfrentamento do trabalho infantil no Brasil.

O objetivo deste artigo é refletir sobre estratégias de enfrentamento da pobreza a partir da exigência de frequência escolar mínima presente no desenho do programa de transferência de renda Bolsa Família. A reflexão aqui proposta será feita em três partes, além desta Introdução.

$\mathrm{Na}$ primeira, serão apresentadas algumas reflexões que, de maneira direta ou indireta, problematizam a efetividade das condicionalidades em educação do PBF. Começaremos com a discussão a respeito da Teoria do Capital Humano e se a exigência de frequência escolar mínima propiciaria condições de incremento deste capital para os que participam do PBF. A própria incorporação de conceitos da Teoria do Capital Humano, nos programas de transferência de renda, também será discutida nesta parte. Na sequência, a partir das reflexões de Pierre Bourdieu (Bourdieu, 2010), serão colocadas em xeque as possibilidades de ascensão e mobilidade social a partir da frequência escolar uma vez que, no entendimento do sociólogo francês, a escola é uma das instituições que mais contribuem para a manutenção das desigualdades sociais. A correlação entre ganhos de escolaridade e maiores oportunidades de emprego será problematizada, tendo por base as reflexões de Robert Castel (CASTEL, 1998). Este autor considera que a chamada crise da sociedade salarial impõe um novo e importante desafio para as sociedades contemporâneas: a possivel não empregabilidade dos qualificados. Ainda nesta parte, discutiremos alguns trabalhos que, de maneira especifica, problematizam a efetividade das condicionalidades em educação em programas de transferência de renda. São os casos da pesquisa de Célia Kerstenetzky e Alessandra Brito (KERSTENETZKY; BRITO, 2011) que tratam dos efeitos do PBF na redução do trabalho infantil. Outros autores, como Fernando Reimers, Carol da Silva e Ernesto Trevino (REIMERS; SILVA; TREVINO, 2006) e Lívia Vilas Boas (VILAS-BÔAS, 2011), chamam atenção para o fato de

\footnotetext{
2 "Na área da educação, todas as crianças e adolescentes entre 6 e 15 anos devem estar devidamente matriculados e com frequência escolar mensal mínina de $85 \%$ da carga horária. Já os estudantes entre 16 e 17 anos devem ter frequência de, no mínimo, 75\%" (MINISTÉRIO DO DESENVOLVIMENTO SOCIAL E COMBATE A FOME, 2011).
} 
que a efetividade da frequência escolar, como forma de superação da pobreza, deve levar em conta a questão da qualidade do ensino oferecido, algo que está ausente no desenho dos Programas Transferência de Renda Condicionadas. Esta primeira parte se encerra com a pesquisa de Marcelo Medeiros, Tatiana Britto e Fábio Soares (MEDEIROS; BRITTO; SOARES, 2007). Ao compararem informações dos beneficiários do PBF com os do Benefício de Prestação Continuada (BPC), programa de transferência de renda sem exigência de condicionalidades, os autores indagam se a a exigência de frequencia escolar mínima seria uma variável significativa para determinar maior acesso à educação. ${ }^{3}$

Na segunda parte do artigo, apresento algumas considerações, tendo em vista a pesquisa que venho desenvolvendo junto aos beneficiários do PBF residentes em Campinas (SP) desde 2008. Buscarei salientar significados simbólicos, até certo ponto não previsto, das condicionalidades quando se levam em conta as visões dos participantes do PBF. Os entrevistados não ignoram os possíveis efeitos práticos de colocarem e manterem os seus filhos na escola. Todavia, as entrevistas sugerem que o cumprimento desta condição, para receber o benefício do PBF, instaura também uma relação de troca e de reciprocidade entre os beneficiários e o Estado que pode ser interessante se considerarmos os vínculos sociais que derivam desta relação. Assim, o desenvolvimento do artigo nos levará a sugerir que as condicionalidades da educação, presentes no PBF, podem ser questionadas se as considerarmos exclusivamente como formas de superação da chamada transmissão da pobreza intergeracional. No entanto, como política social mais ampla, os vínculos sociais instaurados pelos ciclos de troca e reciprocidade entre as famílias e o Estado trazem efeitos positivos, sobretudo em termos de ganhos políticos e no senso de pertencimento social por parte das beneficiárias.

$\mathrm{Na}$ terceira e última parte, as reflexões apresentadas ao longo do texto serão sintetizadas na conclusão.

\section{Frequência escolar e o enfrentamento da pobreza}

As condicionalidades em relação à educação e à saúde do PBF foram estabelecidas com o propósito de contribuir para o aumento das capacidades das pessoas, tendo em vista o combate à pobreza. 0 pressuposto desse entendimento é que os filhos dos mais pobres, por meio do acesso aos serviços de educação e saúde, ampliariam seu Capital Humano e, assim, obteriam maiores possibilidades de ingressar no mercado de trabalho, gerar renda e sair da condição de pobreza quando adultos.

3 O Benefício de Prestação Continuada (BPC) é "um benefício individual, não vitalício e intransferivel, que assegura a transferência mensal de 1 (um) salário mínimo ao idoso, com 65 (sessenta e cinco) anos ou mais, e à pessoa com deficiência, de qualquer idade, com impedimentos de longo prazo, de natureza física, mental, intelectual ou sensorial, os quais, em interação com diversas barreiras, podem obstruir sua participação plena e efetiva na sociedade em igualdade de condições com as demais pessoas. Em ambos os casos, devem comprovar não possuir meios de garantir o próprio sustento, nem tê-lo provido por sua família. A renda mensal familiar per capita deve ser inferior a - (um quarto) do salário mínimo vigente.” (Ministério do Desenvolvimento Social, 2012). 
Ana Fonseca (FONSECA, 2001) e Eduardo Suplicy (SUPLICY, 2004) indicam que o formato de utilizar a transferência de renda com forma de romper a chamada transmissão intergeracional da pobreza surgiu no Brasil a partir das contribuições do economista José Márcio de Camargo às propostas iniciais dos Programas de Garantia de Renda Mínima, encabeçadas por algumas prefeituras municipais nos anos noventa do século XX. Na visão de Camargo (CAMARGO, 1991), dada as carências socioeconômicas de grande parte da população, as crianças são estimuladas a trabalhar em idade precoce para contribuir com a renda familiar. Tal fato criaria um círculo vicioso já que elas, ao entrarem cedo no mercado de trabalho, diminuiriam a sua escolaridade e reduziriam drasticamente suas chances de sair da pobreza quando adultas. Como forma de romper este ciclo de transmissão intergeracional, o Estado deveria garantir uma renda familiar compatível com acréscimo gerado pelo trabalho infantil, de maneira a possibilitar o incremento da escolaridade das crianças e aumentar suas chances de sairem da pobreza quando adultas.

0 entendimento que condiciona a transferência de renda à exigência de frequência como forma de enfrentar a pobreza, presente no desenho do PBF e em outras políticas de transferência de renda condicionadas, tem sido objeto de várias discussões. Sem ter a pretensão de esgotar esse assunto, passemos, para uma breve caracterização de algumas contestações.

Uma primeira objeção repousa no fato de que este entendimento restringe a Escola e os respectivos curriculos escolares a meros instrumentos que possibilitam a obtenção de um conjunto de habilidades e destrezas, sob o desígnio de Capital Humano, que permitiria as pessoas a melhorarem sua produtividade na sociedade, com consequente incremento de suas rendas. É importante salientar que a Teoria do Capital Humano surgiu, em meados da década de sessenta do século passado com os escritos de Theodore W. Schultz (SCHULTZ, 1968), dentro de um debate acadêmico que buscava repensar a forma como pensamento econômico clássico explicava o aumento da produção das sociedades ocidentais desenvolvidas do pós-guerra (LÓPEZRUIZ, 2007). De maneira muito esquemática, à Teoria do Capital Humano, entende que as diferenças nas capacidades adquiridas pela mão de obra ao longo do tempo são tributárias dos investimentos feitos no trabalho, entendido como capital. Como qualquer tipo de investimento, aquele realizado em si mesmo deve proporcionar um retorno futuro para seu proprietário. É nesse ponto que entra a educação dentro da Teoria do Capital Humano, que passa a ser concebida como um bem intermediário, portanto investimento, cujo consumo promoveria o incremento de um conjunto de habilidades e destrezas, formadoras de capital humano. Assim, "investimento em cursos e treinamentos especializados (...) produzirão um retorno futuro em termos de maiores ganhos e satisfações para essa pessoa" (LÓPEZ-RUIZ, 2007, p. 200).

A incorporação da Teoria do Capital Humano nos programas de transferência de renda condicionadas compreende que o Estado deve ser o agente financiador 
do investimento em educação, sobretudo para crianças e jovens de famílias pobres. 0 retorno deste investimento será dado pelo incremento da renda dessas pessoas quando estas estiverem aptas para venderem sua força de trabalho mais valorizada. Pode-se afirmar que este tipo de entendimento restringe a educação como um investimento o qual será valorizado ou não a depender das forças do mercado das sociedades capitalistas. Assim, deixa de ser fundamental nos processos educativos a formação da pessoa, num sentido mais amplo, para se valorizar a transmissão de um conjunto de habilidades e destrezas. ${ }^{4}$ É a partir desta vertente que se observam criticas a Teoria do Capital Humano relacionadas aos Programas de Transferência de Renda. Ana Fonseca reproduz um trecho extraído de um texto de Alain Bihr que, em boa medida, sintetiza essas objeções:

Os economistas, os gestores, os políticos - assim como o cidadão comum que adotam esta locução [Capital Humano] - manifestam, de fato, toda a falta de humanidade de uma concepção de mundo na qual todos devem medir sua existência pelo critério de que o único valor que vale e pelo qual é necessário se submeter: o valor do mercado. 0 que entendem por "capital humano"? Simplesmente, a força de trabalho dos assalariados: o conjunto das faculdades físicas (...), morais (...), intelectuais (...), estéticas (...), relacionais (...) que os trabalhadores podem vender no mercado de trabalho (...) Aqueles que designam a força de trabalho como "capital humano" pretendem convencer a si mesmos e aos trabalhadores que cada um deles teria também, com sua força de trabalho, um "capital", ou seja, um conjunto de recursos que lhes cabem valorizar ao máximo, cuidando de conservar e inclusive aumentar seu valor por meio de sua educação inicial e continuada, sua experiência profissional, suas relações pessoais etc. Em todas as dimensões de sua existência cada um deveria considerar-se e comportar-se como um centro potencial de acumulação de riqueza monetária, exemplo da empresa capitalista. Todos devem se comportar como um capitalista cujo capital não seria outra coisa a não ser a sua própria pessoa. Todos capitalistas, todos empresários de si mesmos" (BIHR, 1987 apud FONSECA, 2009, p. 38)5

Fernando Reimers, Carol da Silva e Ernesto Trevino (REIMERS; SILVA; TREVINO, 2006) assinalam que um dos problemas da incorporação da Teoria do Capital Humano aos programas de transferência de renda diz respeito ao fato de que a formação escolar e os anos passados na escola não são suficientes para formar este suposto

\footnotetext{
${ }^{4} \mathrm{Na}$ arguta observação de Marilena Chauí, transmissão que preferencialmente deve ser feita "em manuais de fácil leitura para os estudantes, ricos em ilustrações e com duplicata em CDs” (Chaui, 1999)”

5 Tradução livre do autor.
} 
capital. 0 que de fato constitui a formação do chamado Capital Humano não é somente o tempo de permanência na escola ou a obtenção de um diploma (muito embora saibamos que o diploma é um passaporte fundamental para o ingresso em determinadas profissões), mas o desenvolvimento de certas habilidades e destrezas (cognitivas, criativas, performáticas, entre outras) que permitiriam às pessoas melhor desempenho em suas atividades. Este aprendizado não está necessariamente relacionado aos anos de estudo ou à titulação, mas à qualidade do ensino oferecido. Voltaremos a este ponto mais tarde.

A partir de outro contexto, Pierre Bourdieu (Bourdieu, 2010) argumenta ser necessário romper com o entendimento de que a escola é um fator de mobilidade social. Na visão do sociólogo francês, a escola é um dos instrumentos mais eficazes para a conservação da desigualdade social, uma vez que legitima, pela atuação do Estado na elaboração dos currículos escolares, por exemplo, formas de reprodução social que sancionam a herança cultural como um dos fatores mais relevantes para o sucesso dos indivíduos. De fato, o sistema escolar, na visão de Bourdieu, trata como iguais os desiguais e assim contribui fortemente para a legitimação da reprodução social de forma excludente. ${ }^{6}$

É preciso ter em mente que para além de uma dominação econômica, stricto sensu, existe também uma dominação simbólica em que os detentores do chamado Capital Cultural estabelecem estratégias para que este seja distribuído de forma desigual. A posse do Capital Cultural implica ganhos de distinção que conferem prestígio àqueles que, por exemplo, dominam a utilização da linguagem (escrita e falada) de maneira "correta", possuem um conjunto de gostos e preferências culturais tidos como elevado, utilizam o corpo e as emoções de forma considerada apropriada, entre outros. 0 domínio destes saberes, atitudes e gostos, que compõem um "habitus" de classe, possibilita a acumulação do capital cultural que é distribuído de maneira desigual, endogamicamente, seja pelas estratégias de casamento, seja pelas de herança.

Numa sociedade igualitária, a escola deveria ter o papel de romper com essa inércia social excludente e oferecer a todos, de maneira indiscriminada, instrumentos para ter acesso ao capital cultural e simbólico que fazem a diferença. Mas, na visão de Bourdieu, não é isso que ocorre. De maneira inversa, a escola contribui de forma decisiva para que as informações que permitem os chamados ganhos de distinção continuem restritas a

6 Interessante notar certas similitudes entre as colocações de Bourdieu e a do economista Paul Krugman, prêmio Nobel de Economia em 2008, num artigo recente em que este último trata a respeito dos debates envolvendo candidatos republicanos no âmbito das prévias eleitorais dos EUA em 2012. Para Krugman, "os americanos acham que vivem numa meritocracia, mas essa imagem que eles têm de si mesmos é uma fantasia. Segundo reportagem do New York Times da semana passada, os EUA são o país desenvolvido que dá mais valor à origem familiar e onde os que vêm de camadas inferiores têm menos chances de ascender ao topo (...) Quando se trata do ensino superior, poucos das classes baixas conseguem entrar em universidades. Em escolas mais seletivas, $74 \%$ dos jovens que ingressam vêm dos 25\% de famílias ricas. Só 3\% dos que chegam vêm dos $25 \%$ da parte de baixo da escala social. Se filhos de camadas inferiores ingressam na universidade, a falta de apoio financeiro faz com eles sejam obrigados a deixá-la com mais frequência do que filhos de ricos” (KRUGMAN, 2012). 
poucos. Neste processo, o Estado tem um papel fundamental no sentido de legitimar um sistema de gostos e preferências específico de um determinado grupo para o conjunto da sociedade. Assim, o estabelecimento de um sistema escolar nacional e unificado tem um peso importante, como demonstra o autor nessa passagem:

Ao impor e inculcar universalmente (nos limites de seu âmbito) uma cultura dominante assim constituída em cultura nacional legítima, o sistema escolar, principalmente através do ensino da história e, especialmente, da história da literatura, inculca os fundamentos de uma verdadeira 'religião cívica' e, mais precisamente, os pressupostos fundamentais da imagem (nacional) de si (...) A unificação cultural e linguística é acompanhada pela imposição da língua e da cultura dominante como legitimas e pela rejeição de todas as outras como indignas" (BOURDIEU, 1996, p. 106-107).

Como já mencionado, a escola trata de forma igual os desiguais. Crianças socializadas num ambiente culturalmente valorizado entram no sistema escolar com muita vantagem em relação àquelas provenientes de outros grupos. A escola, ao invés de corrigir estas distorções produzidas pela herança cultural, legitima o sistema de gostos e preferências dominante e faz com que aqueles que têm uma vantagem competitiva inicial obtenham, ao longo do periodo escolar, um desempenho "naturalmente" melhor do que os outros. Isto porque as crianças das classes baixas e médias são julgadas no sistema escolar segundo a escala de valores dominante. Além disso, grande parte das informações necessárias para aquisição do capital cultural é obtida fora da escola:

[...] pesquisas sobre os estudantes das faculdades de letras tendem a mostrar que a parte do capital cultural que é a mais diretamente rentável na vida escolar é constituída pelas informações sobre o mundo universitário e sobre o cursus, pela facilidade verbal e pela cultura livre adquiridas nas experiências extra-escolares [...]. (BOURDIEU, 2010, p. 44).

Pelo breve exposto, depreendem-se as razões que levam o sociólogo francês afirmar que a escola é conservadora. Longe de representar um instrumento de mobilidade e ascensão social para os mais pobres, a escola reforça as estruturas sociais responsáveis pela manutenção da desigualdade social. Os pobres que conseguem ascender socialmente pela via da escolarização são exceções que comprovam a regra:

0 sucesso excepcional de alguns indivíduos que escapam ao destino coletivo dá uma aparência de legitimidade à seleção escolar, e dá crédito ao mito da escola libertadora junto àqueles próprios indivíduos que ela eliminou, fazendo crer que o sucesso é uma simples questão de trabalho e de dons. (BOURDIEU, 2010, p. 59). 
A partir de outras miradas, Robert Castel (CASTEL, 1998, 2010) salienta para o fato de que as relações entre os indivíduos e a esfera do trabalho têm sido profundamente alteradas nas últimas décadas. Na visão deste autor, os chamados trinta anos gloriosos, que compreendem o período do final da Segunda Guerra Mundial até meados da década de setenta do século $\mathrm{XX}$, caracterizaram-se pelo apogeu daquilo que chamou de sociedade salarial. Como o próprio nome sugere, este período é pautado pelo crescimento e fortalecimento das formas assalariadas de contratação, sobretudo nas economias capitalistas desenvolvidas do Ocidente, com proteção social garantida pelo Estado. A sociedade salarial é uma sociedade de atores coletivos, "o coletivo é quem protege" (CASTEL, 2010, p. 24), vale dizer, grandes categorias de trabalhadores, organizações sindicais, convenções coletivas, entre outras iniciativas, que foram fundamentais para a conquista de uma série de direitos sociais, tais como, salário mínimo, proteções contra demissões, seguridade contra doenças, acidentes de trabalho e aposentadoria.

Mudanças nas regras básicas da acumulação capitalista, observadas a partir de meados da década de setenta, dirigindo-se para formas de produção e de consumo mais flexiveis, abalaram os alicerces da chamada sociedade salarial. Ao invés do emprego estável, em tempo integral e com proteção social, Castel identifica que os individuos do capitalismo pós-industrial terão que conviver com relações cada vez mais aleatórias com o mercado de trabalho. 0 crescimento dos contratos de trabalho em tempo parcial, das formas autônomas e individualizadas de contratação, do trabalho em rede, terceirizado, realizado por tarefas, descontínuo e à mercê das redes de proteção social seriam evidências dessa "Grande Transformação" pelas quais passam as sociedades atuais. Richard Sennett (SENNET, 2006) identificou que nesse novo capitalismo não há mais o sentido de "longo prazo", com profundas consequências para a vida emocional das pessoas, dentro e fora do ambiente de trabalho. Na perspectiva durkheimiana seguida por Robert Castel, as sociedades atuais seriam marcadas por processos de "desfiliação" social, uma vez que os vínculos integradores entre o indivíduo e a sociedade, através dos quais a vida social se reproduz e se renova, não são mais assegurados pela esfera do trabalho.

É fundamental compreender que essas transformações, muito sumariamente descritas, não atingem a todos de maneira indiferenciada, havendo indivíduos que se beneficiam dessa nova dinâmica. Todavia, Castel observa que a precarização crescente das relações de trabalho tem como efeito trajetórias profissionais marcadas pela incerteza. Torna-se importante compreender que mesmo aqueles que estão integrados podem, a qualquer momento, oscilar para o outro lado e engrossar a lista dos desempregados, uma vez que o crescimento do desemprego e da desfiliação não atingem somente os segmentos mais vulneráveis, tais como os trabalhadores com menor qualificação, ou os mais jovens. Para o autor, trata-se de um processo amplo que alcança também os mais qualificados, já que a qualquer momento estes poderão oscilar para o outro lado. 
A dinâmica que recompõe a organização do trabalho e desmorona o emprego estável atravessa o conjunto das situações de trabalho, ainda que afete mais os setores menos qualificados, não preserva os mais qualificados. (CASTEL, 2010, p. 139).

0 contingente crescente de uma parcela de desempregados qualificados na França indicaria a amplitude dessas transformações assim como o prenúncio de um novo e grave problema no futuro: a possível não empregabilidade dos qualificados. Castel sugere a necessidade de se construir novas formas para lidar com essa situação, uma vez que a lógica das políticas públicas que enfatizam a qualificação como o caminho mais adequado para evitar o desemprego está ameaçada (CASTEL, 1998, p. 520). Se seguirmos este raciocínio, é possivel colocar em dúvida a premissa existente no desenho do Programa Bolsa Família de que a exigência de frequência escolar seria um fator determinante para romper o chamado ciclo intergeracional da pobreza. Primeiro, porque a frequência escolar não garante, por si só, maior escolaridade. Segundo, porque a elevação do nível de escolaridade não será mais garantia para obtenção de emprego nas sociedades atuais, de acordo com este entendimento. É importante notar que o autor não é contrário a políticas que visem ao incremento da escolaridade, apenas põe em dúvida a correlação necessária entre ganhos de escolaridade e garantia de emprego, tal como se pode verificar neste trecho:

Entendamo-nos bem: é legítimo e até mesmo necessário do ponto de vista da democracia, atacar o problema das "baixas qualificações" (isto é, numa linguagem menos tecnocrática, acabar com o subdesenvolvimento cultural de uma parte da população). Mas é ilusório deduzir daí que os não-empregados possam encontrar um emprego simplesmente pelo fato de uma elevação do nivel de escolaridade. (CASTEL, 1998, p. 521).

Outra suposta serventia da exigência de frequência escolar para crianças e jovens participantes do PBF relaciona-se ao enfrentamento do trabalho infantil. Dados contidos no suplemento especial do Programa Bolsa Família da Pesquisa Nacional por Amostra de Domicílio (PNAD) de 2006, analisados por Célia Kerstenetzky e Alessandra Brito (KERSTENETZKY; BRITO, 2011), indicam que a porcentagem de crianças entre 10 e 15 anos cobertas pelo programa e que exerceu algum trabalho na semana de referência da pesquisa é significativamente maior quando comparada com crianças da mesma idade não cobertas pelo benefício. Segundo a PNAD de 2006, 15,1\% das crianças entre 10 e 15 anos cobertas pelo PBF trabalharam na semana de referência da pesquisa, ante $8,6 \%$ para o grupo de não beneficiários com a mesma idade. As autoras vêem com preocupação esses números, uma vez que indicam que o valor pago às famílias assistidas pelo PBF não está sendo suficiente para coibir o trabalho infantil, contrariando, portanto, uma das intenções do programa. É o que se pode notar nesta passagem extraída do texto:

Este resultado parece contraditório, uma vez que as famílias que recebem uma transferência de renda condicionada à frequência 
escolar das crianças tenderiam a ter menor proporção de crianças trabalhando relativamente aos que não recebem tal benefício, visto que o não recebimento poderia aumentar a necessidade do trabalho dos filhos como complemento da renda familiar. Portanto, pode-se pensar na possibilidade de o programa Bolsa Família ainda não ter se constituído em um substituto da renda das crianças pertencentes a famílias mais pobre (...) o fato, porém, é que se as crianças seguem trabalhando é porque o valor dos benefícios não tem sido, para um bom número de famílias, suficiente para deter o trabalho infantil. (KERSTENETZKY; BRITO, 2011, p. 28-29).

A discussão sobre a efetividade da exigência de frequência escolar de crianças e jovens, em relação aos propósitos previstos no PBF, deve levar em conta também a qualidade dos serviços educacionais oferecidos no sistema de educação pública brasileiro. Como sugere Célia Kerstenetzky, "a efetividade das condicionalidades é, por sua vez, condicional à disponibilidade e à qualidade dos serviços providos. Uma rápida avaliação dos serviços básicos de educação e saúde no Brasil evidencia, contudo, quão crítica é sua provisão". (KERSTENETZKY, 2009, p. 68).

Fernando Reimers, Carol da Silva e Ernesto Trevino (REIMERS; SILVA; TREVINO, 2006) levantam a discussão sobre a qualidade do ensino oferecido no âmbito dos Programas de Transferência de Renda Condicionados (PTRC). Os autores, que analisaram várias experiências de PTRC implantados no mundo na primeira metade dos anos 2000, dentre os quais o PBF, concluem que esses programas concentram seus esforços no incremento das matrículas escolares, da frequência escolar e/ou no aumento da escolaridade dos que dele participam. É digno de nota que nenhum PTRC analisado tinha como objetivo incrementar a qualidade do ensino através, por exemplo, de melhorias no processo de ensino/aprendizado. Os PTRC partem da premissa, questionada pelos autores, de que os pobres irão aprender mais se ingressarem e permanecerem na escola independentemente da qualidade do ensino oferecido. Assim,

Baseado nos dados analisados neste trabalho, concluimos que há pouca evidência para sustentar a conclusão de que os PTRC são instrumentos educacionais eficazes, em particular, no que diz respeito à sua capacidade de aumentar o aprendizado" (REIMERS; SILVA; TREVINO, 2006, p. 10).7

Se seguirmos a linha de argumentação dos autores, veremos que a educação é compreendida no âmbito dos PTRC como se fosse uma caixa preta, em que os "inputs" e "outputs" são conhecidos mas não as relações causais entre estes. Pressupõe-se que a experiência de se colocar uma criança pobre na escola e fazer com que ela permaneça no sistema escolar trará benefícios no futuro, especialmente em termos

\footnotetext{
7 Tradução livre do autor.
} 
de melhores salários e oportunidades econômicas em relação a uma criança que não frequentou a escola. Todavia, a correlação entre mais anos de estudo e melhores salários não é necessariamente automática, uma vez que é difícil dimensionar se o aprendizado que possibilitou a esta pessoa obter um determinado rendimento foi adquirido na escola ou fora da escola. ${ }^{8}$

0 ponto a ser enfatizado pelos autores é que os PTRC, ao deixarem de lado o enfrentamento da questão relacionada à qualidade do ensino oferecido, não devem ser entendidos como programas de política educacional. Em relação às políticas de bem estar social, os autores consideram que os PTRC representam avanços em relação à outras iniciativas, pois combinam diferentes dimensões de assistência (alimentar, saúde e nutrição) e promovem iniciativas (transferência de dinheiro) que permitem maior autonomia às famílias em decisões que podem beneficiar seus membros. No entanto, ao se levar em conta os custos destes programas, os autores se perguntam se não seria mais eficaz, como política educional, investir esses recursos em programas específicos que focalizem a melhoria da qualidade da educação?

Nosso ponto de partida deste livro é que, sem acesso a uma educação básica de qualidade, Programas de Transferência de Renda Condicionados não podem ser nem justificados, nem eficientes" (REIMERS; SILVA; TREVINO, 2006, p. 29).

Ainda no âmbito da discussão sobre a qualidade dos serviços ecucacionais e sua relação com os Programas de Transferência de Renda, Livia Vilas-Bôas (VILAS-BÔAS, 2011) apresenta uma relevante questão que tende a tornar difícil uma mudança em direção a um ensino de melhor qualidade, especialmente no Brasil. No caso brasileiro, as classes médias não utilizam de maneira maciça serviços de educação e saúde já que, ao se beneficiarem de mecanismos de abatimento tributário, matriculam seus filhos em escolas particulares e possuem planos de saúde privado. Dados apresentados pela autora indicam que em 2008 , 21\% da população brasileira possuia plano de saúde privado e, em 2010, as escolas particulares eram responsáveis por $9 \%$ das matriculas do ensino fundamental. Uma vez que as classes médias são atores importantes no sentido de pressionar a opinião pública e os entes federativos na direção de melhorias nos serviços de saúde e educacionais, a autora conclui:

Essa dinâmica - na qual a classe média, e não só os estratos mais elevados da renda, pouco utilizam serviços e bens sociais no setor público - tende a reduzir a qualidade do sistema, ao retirar grupos com maior poder de barganha política da sua base de clientes e a reduzir a legitimidade do sistema de proteção social universal junto aos contribuintes, reduzindo o espaço para a expansão e melhoria do sistema. (VILAS-BÔAS, 2011, p. 15).

8 Vimos, nos parágrafos anteriores, como Bourdieu e Castel tratam dessa questão. 
Finalizo esta seção chamando atenção para o estudo realizado por Marcelo Medeiros, Tatiana Britto e Fábio Soares (MEDEIROS; BRITTO; SOARES, 2007) que comparou dados sobre escolaridade de crianças participantes de dois Programas de Transferência de Renda brasileiros, um incondicional (Benefício de Prestação Continuada) e o outro com condicionalidades (PBF). Os autores sugerem que a existência das condicionalidades não é uma variável significativa para determinar um maior acesso à educação, uma vez que "os efeitos observados sobre a educação podem estar sendo os mesmos de um programa sem condicionalidade, pois há indicações de que, mesmo na ausência de contrapartidas [caso de beneficiários de outro programa de transferência de renda Benefício de Prestação Continuada - BPC], programa de transferência de renda tem efeitos positivos sobre a escolaridade das crianças" (MEDEIROS; BRITTO; SOARES, 2007, p. 13). Considerando os custos que a fiscalização das condicionalidades representam, sobretudo para os municípios, os autores concluem, "em poucas palavras, não se sabe ao certo quão necessárias são as condicionalidades, quanto se gasta para controlá-las e o que exatamente se ganha com isso" (MEDEIROS; BRITTO; SOARES, 2007, p. 14).

Nesse ponto, retomo a questão que intitula este artigo: afinal, para que servem as condicioalidades em educação do Programa Bolsa Família? Sem ter a pretensão de oferecer uma resposta peremptória à pergunta, penso que as discussões sobre as condicionalidades em educação devem ser pensadas numa perspectiva ampliada, não se restringindo somente aos efeitos práticos, muito embora, como sabemos, esses possam ser muito relevantes para a vida das pessoas. Assim, proponho levar em consideração os significados simbólicos que as condicionalidades adquirem quando se leva em conta a visão dos beneficiários do PBF.

\section{0 cumprimento das condicionalidades como forma de incremento do pertencimento social}

Para refletir sobre usos, até certo ponto não previstos das condicionalidades, por parte de quem recebe o benefício, apresento algumas considerações da pesquisa realizada entre 2008 e 2010 junto a beneficiários do Programa Bolsa Família residentes em Campinas (SP). A principal motivação desta investigação foi compreender a importância do PBF levando-se em consideração as visões dos próprios destinatários e de suas familias. ${ }^{9}$

Entre novembro de 2008 e julho de 2010 foram entrevistadas vinte e duas pessoas participantes do PBF residentes em Campinas (SP) que frequentaram o Centro Público de Apoio ao Trabalhador (CPAT), local administrado pela Prefeitura Municipal de

9 Esta pesquisa teve financiamento da Fundação de Amparo à Pesquisa no Estado de São Paulo (FAPESP), através da linha Auxílio à Pesquisa. 
Campinas onde são feitas as inscrições e acompanhamento dos cadastrados no PBF. ${ }^{10} \mathrm{O}$ atendimento aos participantes do programa no CPAT é dividido de acordo com o local de sua residência de tal maneira que a cada dia são atendidas pessoas que vivem em áreas distintas da cidade. Moradores de todas as regiões foram entrevistados, contudo, não houve preocupação de traçar uma amostra representativa dos participantes do PBF em Campinas. A partir do primeiro contato, feito enquanto a pessoa aguardava atendimento, era marcada uma entrevista na casa dos próprios entrevistados e entrevistadas, às vezes realizada em duas ou três sessões. ${ }^{11}$

0 desenvolvimento desta pesquisa levou-me a considerar que as condicionalidades do PBF podem ser vistas como instauradoras de uma relação de troca e reciprocidade entre os beneficiários desta Política Pública e o Estado. Em outro trabalho (PIRES, 2013) destaco que quatro características observadas nas falas dos entrevistados e entrevistadas sobre o Programa Bolsa Família autorizam esta aproximação. Primeiro, o dinheiro que circula nessa política pública é gasto de maneira formalizada e há uma forte moralidade no sentido de se estabelecer usos corretos e usos errados. Segundo, os indivíduos que participam desta relação não o fazem como representantes de si mesmos, mas como representantes de suas famílias ou do Estado. Terceiro, há o estabelecimento de um ciclo de troca e reciprocidade numa dimensão temporal, em que se configura claramente momento de dar, de receber e de retribuir.

A quarta e última característica merece um destaque especial. 0 ciclo de dons e contradons instaurado produz um compromisso, uma aliança entre os parceiros, uma vez que envolve a formação de sentimentos de pertencimento por parte dos recebedores e da produção de vínculos sociais entre eles e o Estado. Torna-se importante observar na fala de entrevistados e entrevistados que entrar no Programa implica fazer parte de um compromisso, como retrata bem este trecho retirado de uma das entrevistas:

Tipo assim, se você seguir o Programa direitinho, levando a criança pra pesar é um dinheiro garantido. Que nem a faxina, não é um dinheiro garantido. Igual eu falei com ela, antes eu fazia faxina quatro vezes por semana, agora eu faço duas só, então não é um dinheiro garantido. Mas eu sei que se eu seguir o Programa no final do mês o dinheiro vai tá lá.

Quando você fala em seguir o Programa direitinho é?

10 Participaram das entrevistas os seguintes alunos de graduação do curso de Ciências Sociais da Puc-Campinas com Bolsas de Iniciação Científica: Cinthia de Oliveira Cunha, Douglas Nascimento, Fernando Monteiro, Haretha Kazumi Itoman e Marcela Nappi Alvares. Agradeço a coordenadora do Centro Público de Apoio ao Trabalhador de Campinas, Gisleide Abreu, pelo apoio dado durante todo desenvolvimento da pesquisa.

11 Do total de entrevistados, vinte são mulheres e dois homens. A idade dos participantes variou entre 23 e 63 anos, sendo que metade está situada na faixa mais jovem (até 39 anos). Em relação à composição familiar, metade vive em arranjos familiares em torno da família conjugal (cerca de 35\% vivem somente com o cônjuge e filho(a)s e 15\% com cônjuge, filho(a) e outros parentes). A outra metade vive em domicílios monoparentais, dos quais cerca de 30\% são compostos apenas por um dos pais e filhos e $20 \%$ compostos por um dos pais, filhos e outros parentes. 
É levar a criança pra pesar todo mês, não deixar a criança faltar da escola. Isso aí já não acontecia, né? Mas é mais uma responsabilidade, é um compromisso. (entrevistada, 29 anos).

0 trecho indica que participar do PBF implica em fazer parte de um compromisso, poder-se-ia dizer uma espécie de contrato, celebrado entre a entrevistada, como representante de sua família, e o Estado. Não nos esqueçamos de que a noção de compromisso remete a um conjunto de obrigações e ou de comprometimentos assumidos por pessoas que mantêm um tipo de vínculo temporal. "Seguir o programa direitinho" sugere que o cumprimento das condicionalidades produz uma relação entre as partes tidas como mais confiável e duradoura ("dinheiro garantido") em relação à estabelecida, por exemplo, com patrões privados. Assim, percebe-se na fala da entrevistada, que o governo não é apenas um parceiro, mas um parceiro confiável. Se ela fizer a sua parte "direitinho", o governo também faz a dele, numa clara evidência de que o prestígio das duas partes está em jogo nessa relação.

Como se pode notar, na passagem abaixo, a noção de compromisso apareceu também em entrevistas da pesquisa nacional Repercussões do Programa Bolsa Família na segurança alimentar e nutricional realizada pelo Instituto Brasileiro de Análises Sociais e Econômicas.

Os participantes dos grupos focais manifestavam, geralmente, sua aceitação às condicionalidades, ora registrando a importância que elas tinham para garantir a presença das crianças na escola "em lugar de estarem na rua", ora por obrigarem o funcionamento de certos serviços, especialmente os oferecidos em unidades de saúde. Consideraram, ainda, as condicionalidades como compromisso de contrapartida que traz ganhos incontestáveis. (INSTITUTO BRASILEIRO DE ANÁLISES SOCIAIS E ECONÔMICAS, 2008, p. 64-65, grifos meus).

Vê-se no trecho que além da idéia de compromisso, aparece o termo contrapartida no lugar da condicionalidade:

Conclui-se que é inadequado chamar de "condicionalidade" a exigência de filhos e filhas na escola e a frequência aos serviços de saúde, que seriam direitos dessas familias. (...) Mais fiel ao que efetivamente ocorre seria denominar como "contrapartida" os compromissos assumidos pelos (as) titulares com a educação e a saúde da família. (INSTITUTO BRASILEIRO DE ANÁLISES SOCIAIS E ECONÔMICAS, 2008, p. 65).

Pensados nos termos propostos neste texto, contrapartida poderia ser vista como contradons que circulam na relação estabelecida entre parceiros do PBF. 
Serge-Chistophe Kolm, no esforço em estabelecer tipologias das formas de reciprocidade, identificou naquela que chamou de "conexão" algumas caracteristicas sugestivas para ilustrar a idéia de "compromisso" que apareceu nas entrevistas. De forma diversa da chamada reciprocidade de "correspondência ou de equiíbrio", em que o dom deve ser retribuido para restabelecer uma situação inicial de equidade, na chamada "reciprocidade de conexão" o que está em jogo não é um senso de justiça, mas sentimentos de pertencimento e de reconhecimento social, tal como sugerido por Marcel Mauss no famoso Ensaio sobre a Dádiva (MAUSS, 2003). Entende Kolm que a ligação produzida pelas partes envolvidas na reciprocidade de conexão pode se estabelecer independente da circulação de bens materiais. Trata-se de um tipo de troca em que a pessoa se sente vinculada à outra pelo reconhecimento que o "outro" proporciona a ela.

\section{Comentários finais}

Afinal, para que servem as condicionalidades em educação do PBF? Ao longo deste texto, busquei refletir sobre essa indagação sem ter a pretensão de oferecer uma única resposta. Penso que ao considerar os usos que os beneficiários fazem das condicionalidades, pudemos ampliar a discussão dos seus efeitos para além do campo da educação.

Na primeira parte do texto, foi colocado em dúvida se a exigência de frequência escolar seria um fator significativo para romper o chamado ciclo intergeracional da pobreza. Em linhas gerais, vimos que o ingresso na escola e a permanência nela não oferecem, por si só, possibilidades de maior mobilidade social se não for levada em conta a qualidade do ensino oferecido. Discutimos, também, se a frequência escolar propiciaria condições para o incremento do Capital Humano. Vimos que as modernas sociedades ocidentais, tendo em vista a forma como organizam a sua produção e consumo, tendem a ter um contingente cada vez maior de desempregados qualificados pondo em dúvida a correlação entre maior escolaridade e emprego. Vimos também que os valores pagos às familias cobertas pelo PBF não estão sendo suficientes para coibir o trabalho infantil, de acordo com a PNAD de 2006, fazendo com que muitas crianças ou jovens tenham que trabalhar e estudar, ao invés de simplesmente brincar e estudar, comprometendo a educação dessas pessoas. Por último, mas nem por isso menos importante, ganhos de escolaridade entre os que recebem transferência de renda do Estado não estão associados necessariamente à exigência de frequentar a escola. Foram observados incrementos na escolaridade de pessoas que participam de programa de transferência de renda sem condicionalidades, como o é o caso do Benefício de Prestação Continuada.

No entanto, ao levar em consideração os usos que as pessoas fazem das condicionalidades, foi possivel perceber possibilidades de ganhos envolvidos em seu cumprimento que vão além dos efeitos práticos sobre a frequência escolar e a escolaridade dos filhos. Trata-se do fortalecimento dos sentimentos de pertencimento e reconhecimento sociais por parte das beneficiárias dados pela efetividade no cumprimento das condicionalidades previstas no programa. Como já referido em outro 
trabalho (PIRES, 2012), a responsabilidade pelo cumprimento das condicionalidades do programa, assumida como uma tarefa das mulheres, cria condições para que se estabeleçam vínculos entre as titulares do programa e o "mundo externo", notadamente o Estado, sem a intermediação de figuras masculinas como maridos, companheiros ou outros. Ao levar em conta esses aspectos, pudemos considerar também a possibilidade de as mulheres alargarem um tipo de pertencimento que vai além daquele oferecido pela esfera do consumo ou pela maior autonomia nas decisões da casa.

\section{Referências}

BOURDIEU, P. Escritos de educação. Petrópolis: Editora Vozes, 2010.

Razões práticas: sobre a teoria da ação. Campinas: Papirus, 1996.

CAMARGO, J. M. Pobreza e garantia de renda mínima. Folha de São Paulo, São Paulo, dez. 1991.

CASTEL, R. As metamorfoses da questão social: uma crônica do salário. Petrópolis: Vozes, 1998.

El asenso de las incertidumbres: trabajo, protecciones, estatuto del individuo. Buenos Aires: Fondo de Cultura Económica, 2010.

CHAUI, M. A atual reforma do Estado incorpora a lógica do mercado e ameaça esvaziar a instituição universitária: a universidade operacional. Folha on line, São Paulo, maio 1999. Disponivel em: <http://www1.folha.uol.com.br/fol/brasil500/ dc_1_3.htm>. Acesso em: 20 dez. 1999.

COHN, A. O PBF e seu potencial como política de Estado. In: CASTRO, J. A.; MODESTO, L. Bolsa Família 2003-2010: avanços e desafios. Brasília, DF: Ipea, 2010. p. 215-234.

FONSECA, A. M. Familia e Política de Renda Mínima. São Paulo: Cortez, 2001. Transferencias condicionadas, estrategias de combate al hambre y la desnutricion en America Latina y el Caribe. Santiago: FAO, 2009.

INSTITUTO BRASILEIRO DE ANÁLISES SOCIAIS E ECONÔMICAS. Repercussões do Programa Bolsa Familia na segurança alimentar e nutricional: relatório síntese. Rio de Janeiro: Ibase, 2008.

KERSTENETZKY, C. L. Redistribuição e desenvolvimento?: A Economia Política do Programa Bolsa Família. Dados: Revista de Ciências Sociais, Rio de Janeiro, v. 52, n. 1 , p. 53-83. maio 2009. 
KERSTENETZKY, C. L.; BRITO, A. S. Série CEDE de textos para discussão. Rio de Janeiro: CEDE, 2011. Disponivel em: <http://www.proac.uff.br/cede/ s\%C3\%A9rie-cede-de-textos-para-discuss\%C3\%A3o>. Acesso em: 17 jan. 2012.

KRUGMAN, P. Os conservadores e o mito da igualdade de oportunidades. $O$ Estado de São Paulo, São Paulo, p. A8, jan. 2012.

LÓPEZ-RUIZ, O. Os executivos das transacionais e o espirito do capitalismo: capital humano e empreendedorismo como valores sociais. Rio de Janeiro: Azougue Editorial, 2007.

MAUSS, M. Ensaio sobre a dádiva: forma e razão da troca nas sociedades arcaicas. In: MAUSS, M. Sociologia e Antropologia. São Paulo: Cosac \& Naify, 2003. p. 185-314.

MEDEIROS, M.; BRITTO, T.; SOARES, F. Transferência de Renda no Brasil. Novos Estudos, [S.I.], n. 79, p. 5-21, nov. 2007.

MINISTÉRIO DO DESENVOLVIMENTO SOCIAL (Brasil). Benefício de Prestação Continuada. Brasilia, DF: 2012. Disponivel em: <http://www.mds.gov.br/ assistenciasocial/beneficiosassistenciais/bpc>. Acesso em: 08 out. 2012.

MINISTÉRIO DO DESENVOLVIMENTO SOCIAL E COMBATE A FOME (Brasil). Condicionalidades. Brasília, DF: 2011. Disponivel em: <http://www.mds.gov.br/ bolsafamilia/condicionalidades>. Acesso em: 24 jan. 2012.

PIRES, A. Orçamento familiar e gênero: percepções do Programa Bolsa Família. Cadernos de Pesquisa, São Paulo, v. 42, n. 145, p. 130-161, mar. 2012.

Relações de troca e reciprocidade entre os participantes do Programa Bolsa Família em Campinas (SP). Política \&t Trabalho, São Paulo, v. 1, n. 3, p. 171195, abr. 2013.

REIMERS, F.; SILVA, C. D.; TREVINO, E. Where is the "Education" in Conditional Cash Transfers in Education?. Montreal: Unesco Institute for Statistics, 2006.

SCHULTZ, T. W. Valor económico de la educación. México: Unión Tipográfica Editorial Hispano Americana, 1968.

SENNETT, R. A corrosão do caráter: consequências pessoais do trabalho no novo capitalismo. Rio de Janeiro: Record, 2006. 
SUPLICY, E. Renda de Cidadania: a saída é pela porta. São Paulo: Cortez, 2004.

VILAS-BÔAS, L. Série CEDE de textos para discussão. Rio de Janeiro: CEDE, 2011. Disponivel em: <http://www.proac.uff.br/cede/s\%C3\%A9rie-cede-de-textospara-discuss\%C3\%A3o>. Acesso em: 17 jan. 2012.

Recebido em: 20/02/2012

Aceito para publicação em: 19/11/2012

\section{After all, what are the reasons for conditionalities on education in brazilian “Bolsa Família” Cash Transfer Program? Abstract}

This article aims to ponder on poverty fighting strategies, from the minimum school attendance standpoint, present on the design of the "Programa Bolsa Familia (PBF)", a cash transfer program of the Federal Government. Initially, some considerations are made based in scientific studies that problematize the effectiveness of education requirements inherent to the "Programa Bolsa Familia". Following, I present the results of our research, developed between 2008 and 2010, which interviewed twenty-two PBF participants aiming to understand their singular viewpoint regarding this cash transfer program. The result of such investigation lead us to conclude that PBF requirements create an exchange and reciprocity relation between its beneficiaries and the Government. In these terms, I propose in this article that the discussions on the PBF education requirements should be considered within a broadened perspective -thus not restricted to its practical results in terms of school attendance or schooling increase - taking into account also its symbolic effects, notably the strengthening of feelings of belonging and social recognition by the interviewees - generated by the fulfillment of education requirements.

Keywords: Education. Public Policies. Cash Transfer Program. Campinas (SP).

\section{En definitiva, ¿para qué sirven las condicionalidades en educación del Programa Beca Familia?}

\section{Resumen}

Este artículo tiene la finalidad de reflexionar sobre estrategias para enfrentar la pobreza a partir de la exigencia escolar mínima como consta en la concepción del programa de transferencia de renta condicionada "Beca Familia" - "Bolsa familia", en su original - del Gobierno Federal brasileño. En la primera parte, se presentan 
algunas consideraciones, fundamentadas en trabajos científicos, que problematizan la eficacia de las condiciones para educación incluidas en el Programa Beca Familia (PBF). En la secuencia, presento los resultados de la investigación, realizada entre 2008 y 2010, en la cual se entrevistaron a veintidós personas participantes del PBF y cuyo objetivo fue comprender la visión de los propios beneficiarios sobre esta política de transferencia de renta. Lo que se identificó en esa investigación me llevó a considerar que las condicionalidades del PBF pueden ser vistas como instauradoras de una relación de intercambio y reciprocidad entre los beneficiarios de esa política y el Estado. Pensado en esos términos, propongo en este artículo que los debates sobre las condicionalidades en educación del PBF deben ser vistos con una perspectiva ampliada, sin restringirse sólo a sus efectos prácticos en términos de frecuencia escolar o mejoras en los estudios, sino también cuanto a sus impactos simbólicos, manifiestamente, el fortalecimiento de los sentimientos de pertenencia y reconocimiento sociales de las entrevistadas, originados por el cumplimiento de las condicionalidades en educación.

Palabras clave: Educación. Políticas Públicas. Programa de Transferencia de Renta Condicionada. Campinas (SP). 